\title{
IAMJ
}

INTERNATIONAL

AYURVEDIC

MEDICAL JOURNAL

ISSN: 2320-5091

Impact Factor: 6.719

\section{FORMULATION AND EVALUATION OF HERBAL LIPSTICK USING BETA VULGURIS EXTRACT}

\section{$\underline{\text { Mona Patel }}^{1}, \underline{\text { Ojash Patel }}^{2}$}

${ }^{1}$ Assistant Professor, Faculty of Pharmacy, SSSRGI, Vadasma, Gujarat, India

${ }^{2}$ Associate Professor, Faculty of Pharmacy, SSSRGI, Vadasma, Gujarat, India

Corresponding Author: patelmona4795@gmail.com

\section{https://doi.org/10.46607/iamj0309062021}

(Published Online: June 2021)

Open Access

(C) International Ayurvedic Medical Journal, India 2021

Article Received: 30/05/2021 - Peer Reviewed: 09/06/2021 - Accepted for Publication: 10/06/2021

Check for updates

\begin{abstract}
Herbal cosmetics are obtaining acceptance in society because natural products are easy to handle and easy to use. The word "Herbal" refers to symbol of safety which has no adverse effects. The present study was done to formulate and evaluate herbal lipstick as they reduce the side effects and increase the usage of natural colorants. Herbal lipstick is a cosmetic product containing pigments, waxes, oils, fragrance, preservatives, Antioxidants and colours. Lipstick formulation is used to protect and to increase the beauty of lips. It is easy to use and handle by women. Herbal lipsticks have minimum side effects. In herbal lipstick development, there are many natural ingredients or nutrients which are safe for lips and keep it healthy. Herbal lipsticks are free from hazardous chemicals. Herbal Lipstick having many advantages it should be protects lips from dryness and cracking. The formulated herbal lipstick was evaluated with several parameters like smoothness, greatness, melting point, breaking point and $\mathrm{pH}$.
\end{abstract}

Keywords: Herbal cosmetics, Herbal lipstick, side effects, safe, colour. 


\section{INTRODUCTION}

Cosmetics are substance which used to enhance the appearance and/or fragrance of the body. Generally, cosmetics are designed to applicable for the face and hair. Cosmetics are generally mixture of various chemical compounds. Some cosmetics being derived from natural sources such as castor oil. Common cosmetics include Shampoo, Lipstick, Cream, Mascara, Eye shadow, Foundation and skin cleanser. Cosmetics are products designed to cleanse, protect and change the appearance of external parts of our bodies. ${ }^{[1-5]}$ Herbal lipstick is a cosmetic product containing pigments, waxes, oils, fragrance, preservatives, Antioxidants and colours. These lipstick preparations do not damage to our lips and have no side effect. Lipstick having many advantages it should be protects lips from dryness and cracking. It brightens women's smile and provides hydration to our lips. In herbal lipstick development, there are many natural ingredients or nutrients which are safe for lips and keep it healthy. Herbal lipsticks are free from hazardous chemicals. ${ }^{[5-}$ 7]

\section{Experimental Work:}

\section{Ingredients:}

Table 1: Details of Herbal ingredients used in Herbal lipstick

\begin{tabular}{|l|l|l|l|l|}
\hline Sr. No. & Ingredient & Biological source (family) & Quantity taken & Use \\
\hline 1. & Bees wax & Apis mellifera (Apidae) & $9 \mathrm{gm}$ & Thickening agent \\
\hline 2. & $\begin{array}{l}\text { White soft paraf- } \\
\text { fin }\end{array}$ & Petrolium & $9 \mathrm{gm}$ & Base \\
\hline 3. & Olive Oil & Olea europoea (Oleaceae) & $5 \mathrm{ml}$ & Moisturizing agent \\
\hline 4. & Beat root extract & Beta vulguris (Amaranthaceae) & $1 \mathrm{ml}$ & Colouring agent \\
\hline 5. & Acacia & Acacia Arabica (Legumes) & $1 \mathrm{gm}$ & Additive \\
\hline 6. & Orange Juice & Citrus sinensis (Rutaceae) & $1 \mathrm{ml}$ & Antioxidants \\
\hline 7. & Vitamin E & --- & $1 \mathrm{ml}$ & Antioxidants \\
\hline 8. & Lemon juice & Citrus limon (Rutaceae) & q. s. & Antioxidants \\
\hline 9. & Peppermint Oil & Mentha piperita (Lamiaceae) & & Flavoring agents \\
\hline
\end{tabular}

\section{Ideal characteristics of Herbal lipstick: ${ }^{[7-10]}$}

It should be free from contamination.

Easily available and safe to use.

Not irritation or any damage to skin.

Have proper texture, odour, colour and packing, etc.

No colour change during storage.

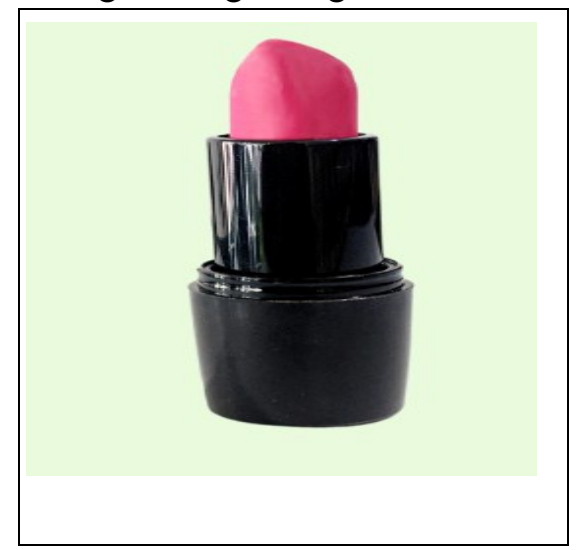

Fig. 1: Herbal lipstick
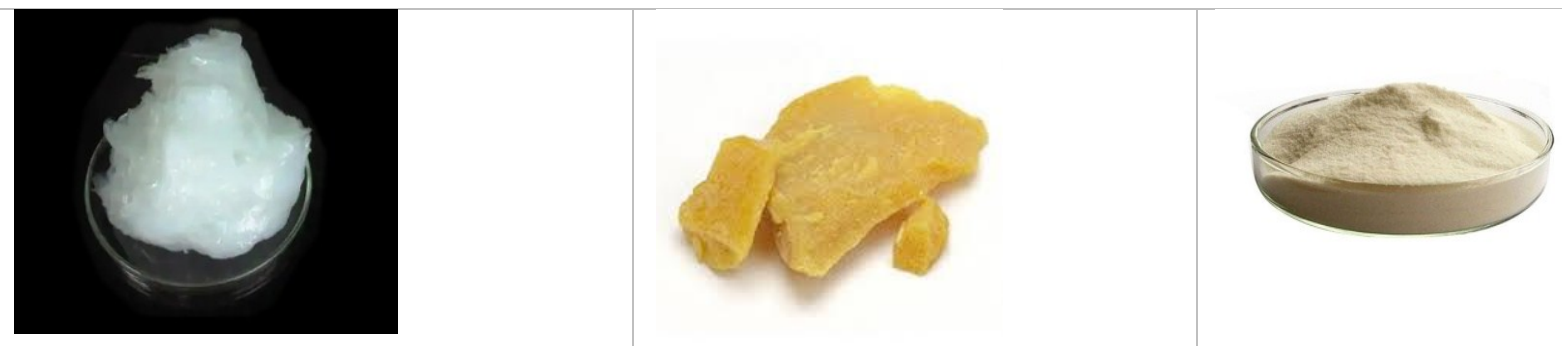


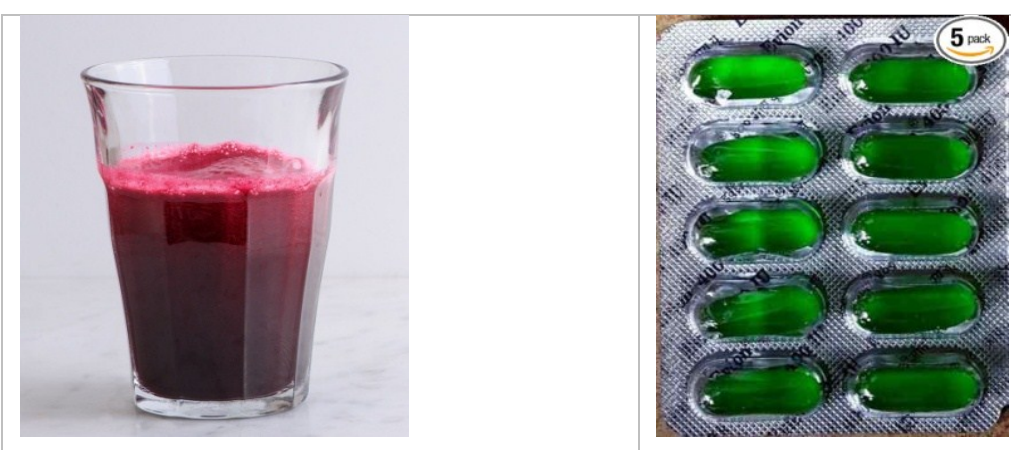

Fig. 2: Herbal ingredients used in Herbal lipstick

\section{[A] Preparation of Beet root extract:}

Washed Beet roots are peeled and chopped

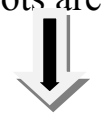

Than Beet roots are blended well. Extract was filtered through a Piece of muslin cloth

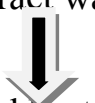

Filtrate of red beet colour obtained

\section{[B] Preparation of Herbal lipstick:}

Weight all herbal ingredients in porcelain dish individually. Then porcelain dish placed on water bath when ingredients are melted Continuously beeswax is mixed with olive oil.

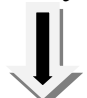

Then add the acacia to the above mixture. Beet root extract and orange juice as well as lemon juice are also added as are colouring agent and preservative

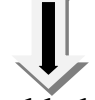

White soft paraffin is added as are moisturizing to lip.

Then added the vitamin $\mathrm{E}$ as are the antioxidant and smoothening agent

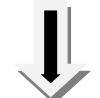

Flavouring agent is peppermint oil is added which have good smell.

Transfer it in mould and Place in the freezer.

Scrap the top layer by sharp knife and remove stick.

Pass the lipstick through the flame is quick fashion it gives gloss to the surface layer of the lipstick.

Performing various evaluation test of prepared lipstick, Place the lipstick in lipstick container and store 


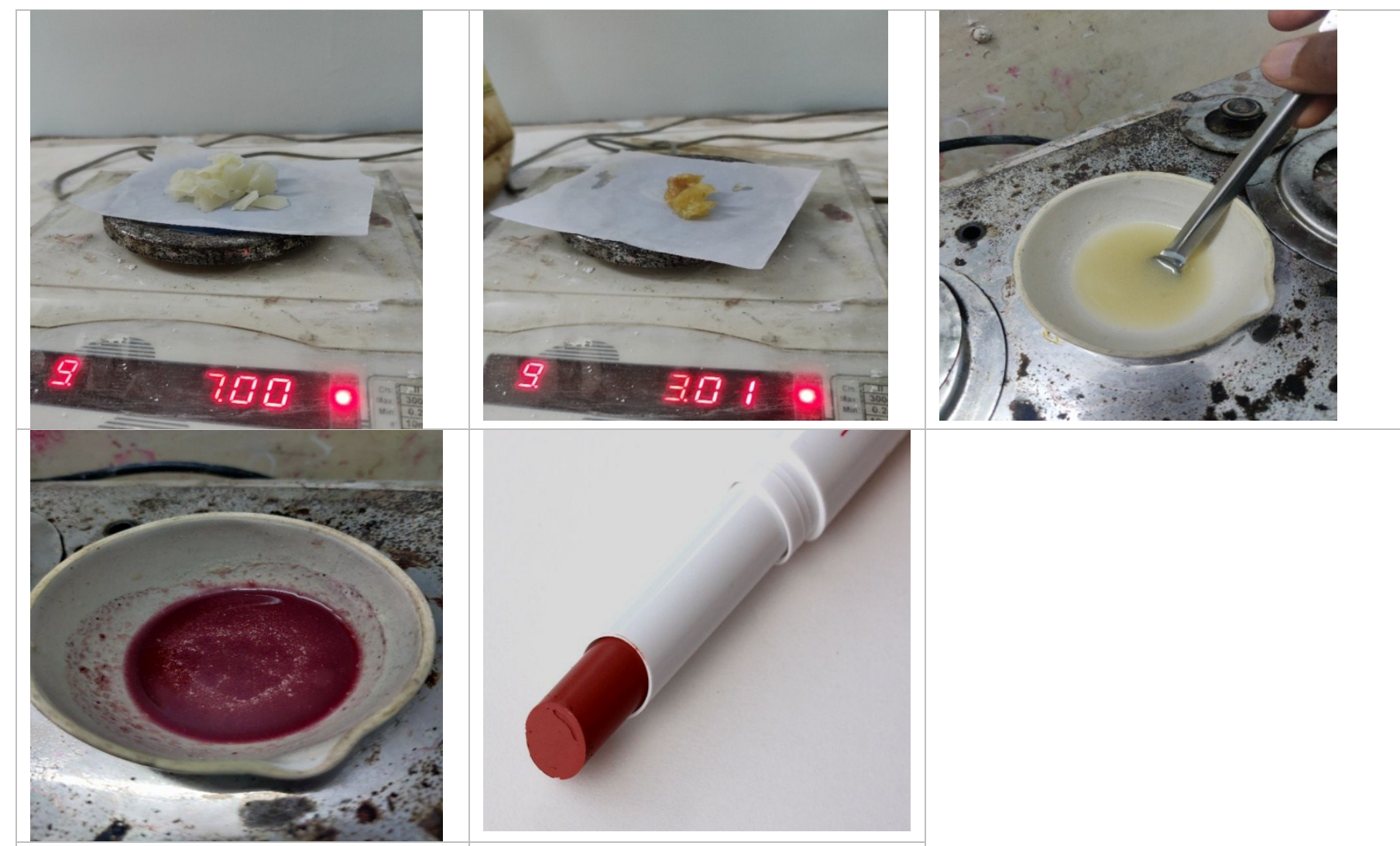

Fig. 3: Weighing, Melting and Fig. 4: Prepared Herbal lipstick Freezing of herbal lipstick during its preparation

\section{Evaluation Parameters ${ }^{11}$}

Colour and texture: Formulated lipstick was checked for colour, glossy and smooth texture.

pH parameter: The $\mathrm{pH}$ of formulated lipstick was determined using digital $\mathrm{pH}$ meter.

Skin irritation Test: It was carried out by applying product on the skin and left for 10 minutes. Found that there was no irritation on skin.

Melting Point Determination Test: The determination of melting point is done in order to determine the storage characteristics of the product. The inciting point of lipstick base should be between 60 to $65^{\circ} \mathrm{C}$ in order to avoid the sensation of friction or dryness during application. Melting point of herbal lipstick is determined by capillary tube method. The capillary is filled with lipstick and attached to the thermometer. At temperature at which lipstick is melted is recorded as Melting point.
Breaking Load Point Test: This test is done to determine the strength and hardness of prepared lipstick. In this method, the lipstick is placed horizontal position 1 inch from the base. Weight is gradually increased loads are attached to it. At Weight at which the lipstick starts to break, known as the breaking load point. The test shall be carried out in specific condition and at about $25{ }^{\circ} \mathrm{C}$ temperatures.

Perfume stability: The formulated herbal lipsticks were tested after 30 days, to record fragrance.

Aging stability: Prepared herbal lipsticks were stored at refrigerator temperature $\left(4^{\circ} \mathrm{C}\right)$, room temperature $\left(20-30^{\circ} \mathrm{C}\right)$ and high temperature $\left(40-50^{\circ} \mathrm{C}\right)$ for 1 hour. Various parameters such as bleeding, crystallization and ease of application were observed.

Force of application: It is test for comparative measurement of the force to be applied for application. 
Lipstick was applied at $45^{\circ} \mathrm{C}$ to cover a 1 sq.inch area until fully covered.

Solubility test: The formulated herbal lipstick was dissolved in various solvents to observe the solubility.

RESULT: Many natural ingredients were used for formulating herbal lipsticks that contain colouring agent which was extracted from the herb Beta vulguris and these lipsticks were evaluated on different parameters. Results of evaluation tests are represented in following table no. 2 .

Table 2: Evaluation result of Herbal Lipstick

\begin{tabular}{|l|l|l|}
\hline Sr. No. & Evaluation parameter & Inference \\
\hline $\mathbf{1 .}$ & Colour & Red \\
\hline $\mathbf{2 .}$ & Texture & Smooth \\
\hline $\mathbf{3 .}$ & Odour & Aromatic \\
\hline $\mathbf{4 .}$ & pH & 6.2 \\
\hline $\mathbf{5 .}$ & Skin irritation & No \\
\hline $\mathbf{6 .}$ & Melting point & $60-62^{\circ} \mathrm{C}$ \\
\hline $\mathbf{7 .}$ & Breaking point & $30 \mathrm{gm}$ \\
\hline $\mathbf{8 .}$ & Perfume stability & +++ \\
\hline $\mathbf{9 .}$ & Aging stability & Smooth \\
\hline $\mathbf{1 0 .}$ & Force of application & Good \\
\hline $\mathbf{1 1}$ & Surface anomalies & No defect \\
\hline $\mathbf{1 2}$. & Solubility test & Soluble in Chloroform \\
\hline
\end{tabular}

\section{CONCLUSION}

Herbal lipstick has been tremendous boost in use of cosmetic by women. It also helps the medicinal that softening, reduce inflammation, moisturizing the lip. In present work, extraction of colour pigment from Beet roots using ethanol was carried out successfully. This colour pigment was collected naturally. The herbal formulation was found to be the best and stable. Hence, from the present study it was concluded that this formulated herbal lipstick was better with minimum side effects or no side effects. From evaluation studies, formulation of lipstick using this natural colorant was more satisfactory than marketed formulation.

\section{ACKNOWLEDGEMENT}

This work was supported by our faculty members to whom we are grateful for their guidance, encouragement and most importantly for believing in our capabilities in order to accomplish this Research work.

\section{REFERENCES}

1. Mittal B.M. and Saha R.N. Handbook of Cosmetics 1st Ed. A Vallabh Prakashan; 2003; 132-56.

2. Sharma P.P. Cosmetics- formulation and Quality Control, 3rd ed. Vandana Publication. 2005:35-54.

3. Jain S.K. \& Sharma N.K. A Textbook of Pharmaceutics. Vallabh Prakashan. 2005; 127-72.

4. Mieloch M, Witulska M. Evaluation of Skin Colouring Properties of Curcuma Longa Extract. Int. J Pharm Sci. 2014, 76(4), 374-8.

5. Savalkar M.B. et al. Formulation \& Evaluation of Herbal lipstick using Amaranthus dubius, J. Pharm. Res., 2018, 7(6), 96-98.

6. Kokate CK, Purohit AP, Gokhale SB. Textbook of Pharmacognosy. 49th ed. Pune: Nirali Prakashan, 2014.

7. Dwivedi Sumeet, Dwivedi Sangeeta and Patel P.C. Formulation, evaluation and antimicrobial activity of herbal lipstick, In Recent Advances in Prospects and Potential of Medicinal Plants, Ed. S. N. Dwivedi, Gayatri Publication, Rewa, 2009, 39-43.

8. Verma shahsi et al. Formulation and evaluation of natural lipsticks prepared from Bixa Orellana seeds and Daucus carota root extract and their comparative 
study, J. Pharma. Sci. Biosci. Res., 2017, 7(1), 131135.

9. Bornare A., Tribhuwan T., Magare S., Shinde A., Tarkase S., Formulation and Evaluation of Herbal lipstick, Int. J. Creative res. Thoughts, 2020, 8(9), 2390-2400.

10. Kurthika S V, Ram S S, Ahmed S A, Sadiq S, Mallick $\mathrm{S}$ D, Sree T R, Formulation and evaluation of natural lipstick from colored pigments of beta vulgarise taproot, J. Pharm. Pharma. Sci., 2014, 3(3), 65-71.

11. Pavani C., Rajeswaree B., Akshara K., Ravali K., Reddy P., Formulation and Evaluation of Herbal lipsticks from Rosa kordesii, Int. J. Sci. Res. Rev., 2019, 8(9), 29-36.

\section{Source of Support: Nil \\ Conflict of Interest: None Declared}

How to cite this URL: Mona Patel \& Ojash Patel: Formulation And Evaluation Of Herbal Lipstick Using Beta Vulguris Extract. International Ayurvedic Medical Journal \{online\} 2021 \{cited June, 2021\} Available from: http://www.iamj.in/posts/images/upload/1175_1180.pdf 